\title{
DA PARANOIA DO CONHECIMENTO À PSICOSE: UMA TRAVESSIA TEÓRICA NO TEXTO DE LACAN
}

\author{
Simone de Fátima \\ Gonçalves \\ Graduada em \\ Psicologia \\ pela Fumec- \\ $\mathrm{BH}$, mestre em \\ Psicologia (Estudos \\ Psicanalíticos) pela \\ UFMG, referência \\ técnica do Centro \\ de Educação em \\ Saúde da SMSA/ \\ $\mathrm{PBH}$, membro \\ correspondente da \\ Escola Brasileira \\ de Psicanálise - \\ Seção Minas/BH.
}

Simone de Fátima Gonçalves

Antônio Márcio Ribeiro Teixeira

Centro de Educação em Saúde da SMSA/PBH, Belo Horizonte, MG, Brasil

Universidade Federal de Minas Gerais, Belo Horizonte, MG, Brasil

Antônio Márcio Ribeiro

Teixeira

Professor adjunto

da Universidade

Federal de

Minas Gerais,

membro da

Escola Brasileira

de Psicanálise e

da Associação

Mundial de

Psicanálise.

Doutor em

Psychanalyse pela

Université de Paris VIII.
RESUMO: Analisamos aqui as bases teóricas que fundamentaram a tese lacaniana do conhecimento paranoico. Ela surgiu como uma torção da tese de doutorado de Lacan de 1932, na qual ele propõe a paranoia como fenômeno de conhecimento; nos trabalhos subsequentes, acaba por estender ao conhecimento humano em geral a pré-condição paranoica. Verificamos que a "paranoia" passa a designar a estrutura mais universal do eu, permitindo a Lacan atribuir a pré-condição paranoica ao conhecimento humano, e, como psicose, uma estrutura clínica. Através de uma análise do esquema ótico, propusemos uma forma de interpretar como conciliáveis as duas noções citadas acima.

Palavras-chave: Conhecimento paranoico, psicose, estrutura.

ABSTRACT: From the paranoia of knowledge to psychosis: a theoretical crossing in the text of Lacan. In this work we analyze the theoretical bases that underlied the Lacanian thesis of paranoiac knowledge. It appeared as a twist of Lacan's doctorate thesis in 1932, where he considers paranoia as a knowledge phenomenon; in his subsequent works he extends the paranoiac precondition to the human knowledge in general. We note that "paranoia" is to designate the most universal structure of the self, allowing Lacan to attribute the paranoiac precondition to the human knowledge, and as psychosis, a clinical structure. Through an analysis of the optic project, we considered one way of interpreting how to conciliate the two concepts mentioned above.

Keywords: Paranoiac knowledge, psychosis, structure.

DOI - http://dx.doi.org/10.1590/S1516-14982015000100008 
A expressão ‘conhecimento paranoico' foi introduzida por Jacques Lacan nos anos que sucederam à sua tese de doutorado, em 1932. Após os anos 1960, não encontramos outras citações sobre o termo nos registros de seus seminários e escritos. Propusemo-nos a seguir o percurso do autor ao longo das elaborações que sustentaram a utilização deste sintagma, até o ponto em que as referências a ele, pelo menos diretamente, esvaziaram-se.

O conhecimento paranoico, na verdade uma tese sobre o tema, aparece em poucos textos de Lacan, entre 1935 a 1960, dos quais selecionamos alguns para esta análise. A primeira referência ao termo ocorre em uma resenha sobre o livro de Minkowski, Compte rendu de le temps vecu (LACAN,1935/1936), mas as bases de sua construção encontram-se em $O$ estádio do espelho como formador do eu (1936-1949/1998). O termo ganha ainda um acréscimo em Formulações sobre a causalidade psíquica (1946/1998), e é retomado em Some reflexions on the ego (1953), sendo esses trabalhos referentes ao período que concerne à elaboração de sua teoria do imaginário. Contudo, a tese é resgatada no Seminário 3, em "O Outro e a psicose” (1955-56/2002), quando o autor já opera sua leitura teórica à luz do estruturalismo, dimensionando o registro do simbólico. Por fim, é citado pela última vez em Subversão do sujeito e dialética do desejo no inconsciente freudiano (1960/1998).

O conhecimento paranoico surge como consequência de uma torção ${ }^{1}$ dos conceitos formados por Lacan em sua tese de doutorado em medicina (Da psicose paranoica em suas relações com a personalidade,1932/1987), na qual vai estabelecer a paranoia como um desenvolvimento de personalidade. Para tal, apoiou-se em recursos conceituais que buscou em disciplinas externas à psiquiatria (antropologia, filosofia, sociologia, biologia, psicanálise e outras), desdobrando a formação da personalidade em uma tripla função estrutural: o desenvolvimento, a concepção de si mesmo e certa tensão nas relações sociais. Este tripé é a referência descritiva para o desenvolvimento normal e, também, para a construção dos delírios sistematizados.

Lacan selecionou para análise, dentre outros, o caso de Aimée, que não se ajustava à definição de Kraepelin de paranoia e, consequentemente, exigia uma redefinição da afecção: ao contrário do enunciado no conceito do psiquiatra clássico, a paciente apresentou uma irrupção relativamente brusca do delírio, marcando uma clara descontinuidade com seu caráter prévio e um retorno ao mesmo depois da passagem ao ato homicida e da sua detenção. Verificou-se ainda, na evolução de sua enfermidade, a conservação da claridade e da ordem do pensamento, do querer e da ação, sem apresentar um desenvolvimento insidioso nem a inquebrantabilidade do delírio (LACAN, 1932/1987).

\footnotetext{
${ }^{1}$ A palavra 'torção', neste texto, é empregada conforme seu uso na psicanálise, com um sentido topológico, segundo o qual o giro das figuras, assim como das ideias, permite uma visão mais ampliada.
} 
A partir da análise deste caso, ao colocar acento na reversibilidade do quadro delirante, Lacan vai propor a paranoia como uma síntese discordante da personalidade de desenvolvimento normal, como um fenômeno cognitivo total, ou seja, como fenômeno do conhecimento. Afasta, dessa forma, a paranoia de um déficit, aproximando-a do conhecimento, como uma constituição histórica das inter-relações entre o indivíduo e seu meio, endereçando a questão da origem à interface com o campo social.

Nos trabalhos que sucederam esta tese, ratifica a afirmação anterior - a equiparação do conhecimento normal à paranoia —, propondo-a como um fenômeno cognitivo, para ampliá-la ao conhecimento humano em geral, dando a este desdobramento a nomeação de conhecimento paranoico.

O eixo dessa mudança se coloca nas construções sobre o estádio do espelho, que acaba por desembocar no percurso pelo qual se forma o ser humano, sob o olhar de Lacan: em uma identificação com seu semelhante através do reconhecimento da própria imagem, estabelecida frente à experiência de um desconhecimento fundamental. Nesta diretriz, publica $O$ estádio do espelho como formador da função do eu (1936-1949/1998), como uma revisão do proposto por ele antes. Neste trabalho, abordará a função do eu na experiência psicanalítica, diferenciando-a do cogito cartesiano pela introdução do sujeito do inconsciente aos moldes freudianos. Esta concepção, no entanto, passa ainda por pelo menos três momentos de revisão ao longo de seus trabalhos: durante a elaboração da teoria do imaginário (1938-1953), no desenvolvimento do registro do simbólico (1953-1964) e, finalmente, com a introdução da dimensão do real (1964-1980). Interessam-nos os dois primeiros momentos na elucidação das proposições sobre o conhecimento paranoico.

Este primeiro momento de elaboração do registro especular terá como referência o espelho plano, matriz na qual Lacan situa a Imago como o eixo da causalidade psíquica: instante da primeira identificação e da alienação imaginária. O segundo momento concerne à determinação do imaginário pelo simbólico com a introdução do Outro, instante de uma segunda alienação mais radical que a primeira, sendo o esquema ótico o que dará forma a esta estrutura.

Consideramos, a princípio, a primeira elaboração, na qual Lacan vai estabelecer a função da Imago. ${ }^{2}$ Ele parte das experiências de Wolfgang Köhler com chimpanzés, conforme retomadas por Henri Wallon: o símio supera, em inteligência instrumental, a criança humana no primeiro ano de vida; portanto,

\footnotetext{
${ }^{2}$ Imago, termo retomado por Lacan, conforme seu conceito pela psicologia analítica: “Termo produzido por Jung em 1911-12 e adotado na psicanálise. Quando Imago é usado no lugar de imagem, serve para sublinhar o fato de que as imagens são geradas subjetivamente, em particular as que se referem a outras pessoas. Isto é, o objeto é percebido de acordo com a dinâmica interna do sujeito" (SAMUELS,1986, p.101).
} 
ocorre uma diferença peculiar frente à exposição de ambos diante do espelho, sendo este o ponto que captura o filósofo e, posteriormente, Lacan.

O chimpanzé, ao perceber o reflexo no espelho, afasta-se simplesmente; a criança humana é tomada por júbilo, seguido de um permanente interesse. Henri Wallon utiliza essa diferença para considerar a prova do espelho como momento constituinte da noção de corpo próprio, e, à luz da gestaltheory, propõe também a personalidade formatada no esquema corporal como um todo, e não como uma soma de elementos díspares, em uma estrutura ou em uma situação total experimentada na continuidade essencial das condições internas e externas (WALLON, 1971).

O ponto de partida para as elaborações wallonianas são as premissas físico-fisiológicas da consciência corporal. Elas se dividem em três domínios fundamentais: o domínio interoceptivo (das sensações viscerais), o proprioceptivo (que corresponde às sensações ligadas ao equilíbrio, às atitudes e aos movimentos), e, por fim, ao extereoceptivo (voltado às sensações exteriores). No recém-nascido, estes domínios são dissociados por causa da ausência de mielinização das conexões interfuncionais; esta formação se iniciará por volta dos três meses e será concluída ao fim do primeiro ano de vida. Isso explica porque a criancinha não pode fazer a distinção entre o que provém do mundo exterior e o que pertence a ela própria.

Henri Wallon descreve três etapas na experiência da criança frente ao espelho: nos primeiros três meses, a indiferença entre a imagem e o real; nos dois meses subsequentes, produzem-se as manifestações mímicas e afetivas do reconhecimento da imagem como tal; e a partir do sexto mês, um pleno período de conexões intersensoriais com o retorno de sua pessoa na imagem do espelho: um ato de conhecimento.

Lacan vai rever o esquema de Wallon sob a ótica da libido freudiana, e situar o eu como ligado à imagem do próprio corpo. A experiência de uma criança de seis a 18 meses diante do espelho localiza uma discordância entre o que ela experimenta (um corpo impotente e vivido de forma desconexa) e sua imagem (unificada) refletida. A noção da prematuração específica do nascimento humano, quando o ponto mais importante é o inacabamento de seu sistema piramidal, dará as coordenadas dessa relação com a imagem: sendo a criança ainda impotente no controle motor, ela antecipa uma totalidade e uma potência na sua imagem refletida no espelho. Matriz simbólica da qual emerge o eu, e na lógica freudiana uma nova ação psíquica, momento de união das pulsões parciais, instante formador do eu e da primeira identificação. ${ }^{3}$

\footnotetext{
${ }^{3}$ Lacan define identificação no texto sobre o estádio do espelho como "a transformação produzida no sujeito quando ele assume uma imagem” (1949/1998, p.97).
} 
Em 1932, em sua tese de doutorado, Lacan toma emprestado o conceito do biólogo alemão Jakob Von Uexküll, de Umwelt - que define o mundo tal como é vivido por cada espécie, onde cada indivíduo constitui um centro ativo. Já em 1949, nas construções do estádio do espelho, opera com a leitura do fenômeno mental em relação ao mundo não mais como um simples fato psíquico, mas como Imago, um conjunto de representações inconscientes que aparecem sob a forma mental de um processo mais geral.

$\mathrm{Na}$ fase do espelho, a relação entre o Innenwelt (interior do organismo) e o Umwelt (próprio de cada organismo em relação ao mundo) é dada a partir da interface entre o ser e a realidade, pois o encontro do indivíduo com o ambiente não ocorre de forma direta: nele, a visão opera como articulador. Nesta elaboração, Lacan se utiliza dos trabalhos de Roger Caillois para estabelecer a diferença da função da imagem no homem e no animal. Considera que, no primeiro, ela opera efeitos sobre o psiquismo, promovendo uma alienação à própria imagem, e, no segundo, a Gestalt tem efeitos formadores sobre o organismo.

É o espelho plano, na experiência com o infans, que vai fornecer a estrutura da Imago como virtualidade subjetiva. Esse espelho divide o espaço em dois: um real, onde nós nos situamos, e outro virtual (atrás do espelho, um espaço subjetivo), onde são produzidas as imagens. A produção da imagem de um objeto supõe que cada ponto do objeto real corresponda a um ponto do objeto imaginário (lei ótica da correspondência biunívoca), e isto define as imagens virtuais, ou seja, as produzidas pelo espelho, conforme ilustrado na figura 1:

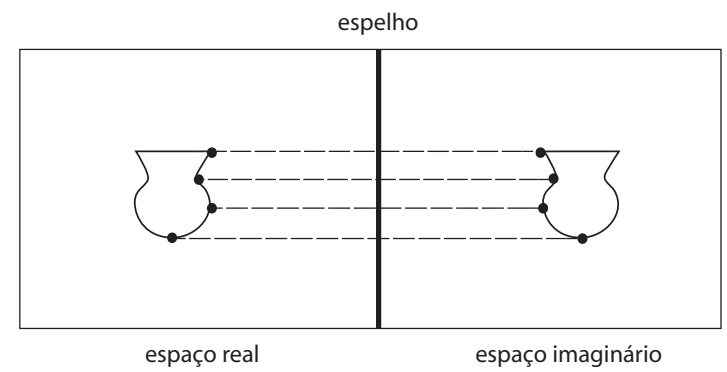

Figura 1. Espelho plano (VODOVOSOFF, 1993, p.25)

A forma total do corpo e a miragem na qual se precipita o eu constituem-se numa exterioridade, em uma Gestalt fundante. Da vivência de um corpo despedaçado (corps morcelé) ${ }^{4}$ à Urbild unificadora, a criança é capturada nesse ponto: ela

\footnotetext{
${ }^{4}$ Termo recuperado por Lacan da teoria de Melanie Klein, correlato à angústia infantil na posição paranoica. Ela propõe que os mecanismos próprios da psicose existem em todo ser humano em fases diferentes de sua evolução: parte da dualidade das pulsões que induz na origem da vida do sujeito uma clivagem do objeto que está no princípio de um jogo entre
} 
é a imagem ideal de si, uma imagem alienante. Portanto, essa imagem externa à criança, seja aquela do espelho de estanho ou a do seu semelhante, é apreendida fora como outro, e do lado da criança, da experiência vivida, permanece um desconhecimento sobre si, que só pode se formular externamente. Essa Gestalt pode ser atestada pela biologia: nos animais, a imagem opera efeitos formadores e afeta a relação do indivíduo com o meio; já no homem, ela é fundante da dinâmica subjetiva.

Contudo, o estádio do espelho, tendo como protótipo a imagem da forma total do corpo conforme percebida, permite ao sujeito suprir a falta de controle real dada pela prematuração, motivo de sua “azáfama jubilatória” (LACAN, 1949/1998, p.97). A relação com o corpo real ainda impotente dá-se por meio do controle fornecido por uma miragem: uma ilusão que funda o eu e estabelece sua formação ligada a uma função de desconhecimento. Uma identificação alienante que fornecerá a unidade do eu, e, assim, é através dos olhos deste pequeno outro que o sujeito vai conhecer-se e também aos objetos do mundo. Assim, todo objeto de desejo só poderá aparecer onde o eu se constitui: na imagem, em frente, possuído pelo outro. Essa tensão subjacente ao imaginário é fonte do ciúme e da rivalidade e, em consequência, da agressividade própria ao narcisismo, pelo fato do objeto de desejo ser externo e inalcançável: ele é fatalmente possuído pelo outro. É da lógica especular, apoiado na leitura de Hegel orientada por Kojève, que Lacan deduz a fórmula do desejo como desejo do outro, e também abandona a ideia da personalidade em favor da consciência de si (VODOVOSOFF, 1993).

Lacan nos remete a Hegel, ao resgatar que o desejo do homem é o desejo de ter reconhecido seu desejo, e que este se constitui sob o signo da mediação. Para ele, Hegel deu a teoria para sempre da função da agressividade na ontologia humana. No nascimento do eu, ele encontra o conflito que Hegel colocou no princípio de todo o progresso da história - aquele que opõe duas consciências de si em uma luta à morte, cuja aposta é a de se fazer reconhecer pelo outro. A consciência de si só é enquanto ser reconhecido. Sua verdade reside, então, na outra consciência que poderá reconhecer: o reconhecimento exige que cada uma de duas autoconsciências, pondo-se em posição de sujeito, atue em relação à outra, colocada em posição de objeto, e, simultaneamente, atue da mesma forma em relação a si própria, colocando-se também em posição de objeto (COUTO, 1999).

\footnotetext{
o bom objeto e o mau objeto. Quer seja parcial como o seio, os excrementos ou o pênis, ou total (imagem de uma pessoa), o objeto é sempre uma Imago; a imagem de um objeto real que o sujeito integrou a seu eu, segundo um mecanismo de introjeção que o eleva ao estatuto de uma fantasia. Sob a pressão da angústia de uma destruição interna, o ego infantil, ainda pouco coerente, experimenta a sensação de uma desintegração iminente, que encontra sua expressão máxima privilegiada na fantasia do corpo despedaçado: corps morcelé (GEETS, 1977, p.85-105).
} 
Desse encontro decorre a submissão de uma consciência à outra - o que Hegel analisará em um discurso sobre o trabalho, através das figuras históricas do mestre e do escravo — ou o reconhecimento mútuo, possibilidade que exige a intervenção de um elemento terceiro, o Outro, que Lacan situará no registro simbólico. No horizonte do impasse imaginário, perfila-se o Mestre Absoluto, a morte, como saída falhada para o problema do reconhecimento entre as duas autoconsciências (idem). No conflito do mestre-escravo, é o reconhecimento do homem pelo homem que está em jogo, ou ainda, sob o olhar de Lacan, é a paixão da alma por excelência, o narcisismo, a loucura pela qual o homem se acredita um homem que se coloca aí em jogo no campo do inconsciente.

Lacan parte do transitivismo para recortar a reação do sujeito infantil diante do espelho, para além de um dinamismo libidinal, e localizá-la como determinante de uma estrutura ontológica do mundo humano: a criança, ao bater e se dizer batida, atesta a alienação primitiva do conhecimento humano em uma matriz paranoica na qual o eu antecipa toda a operação de cognição, pois a criança não mente. Ela é o outro literalmente, e dessa alienação se deduz o fato de o mundo humano acabar sendo uma proliferação de objetos, porque o que é visado não é o objeto, mas o desejo do outro: origem do desejo humano, conforme retomado na dialética hegeliana à luz do inconsciente.

A premissa paranoica é anexada ao conhecimento humano por Lacan, pelo fato da eleição dos objetos no homem acontecer através do eu, ocorrendo sempre no imaginário, em um caráter virtual, cuja função de desconhecimento é constitutiva: é pelos olhos do outro que conhecemos o mundo; portanto, desconhecemos que somos um outro. Instante transitivista da fundação do eu, matriz de onde emerge a dialética do devir do ser, conforme se expressa Lacan na linguagem filosófica. Neste momento de seu ensino, a paranoia inicial é pré-condição para o conhecimento. ${ }^{5}$

\footnotetext{
${ }^{5}$ Simanke esclarece que Lacan vai procurar subsídios para distinguir o imaginário do ilusório no plano científico-clínico, e, com isso, buscar uma visão não deficitária do imaginário. Ele se refere à visão espinozista do imaginário e também às formas distintivas de conhecimento: "a teoria espinozista do conhecimento admite três formas ou níveis do conhecimento. O primeiro é o da experiência vaga ou confusa que decorre da interação do corpo com os outros corpos e opera basicamente com imagens. O segundo se constrói a partir deste primeiro nível, através da generalização das características que todos os corpos, quando considerados sob o modo da extensão, têm em comum; formam-se assim, as 'noções comuns' que integram o conhecimento científico. O terceiro gênero de conhecimento consiste na aproximação intuitiva da totalidade deste sistema de ideias que pode ser alternativamente chamado de Deus ou Natureza. Correspondem a cada nível de conhecimento, respectivamente, as ideias confusas, as ideias adequadas e as ideias intuitivas". Lacan descarta, assim, o objeto imaginário como erro da imaginação, e aponta o conhecimento como mediado pelo corpo (SIMANKE, 2002, p.286-287).
} 
Assim, ele vai caracterizar o conhecimento humano como um elemento de inércia em oposição à dialética, desde a concepção hegeliana. Os termos unidade, permanência e substancialidade, com os quais Lacan define o conhecimento paranoico, dão a ideia de algo que, em vez de deslizar dialeticamente, apresenta uma repetição cristalizada. Trata-se de uma inércia no movimento de reconhecimento dos objetos e do próprio eu numa estrutura estagnada, na qual os objetos se multiplicam de maneira análoga como em um labirinto de espelhos onde as imagens se reproduzem ao infinito, suspendendo, em sua estereotipia, o movimento dialético (GODOY, 2004).

Todavia, ao atribuir realidade às imagens que constituem seu mundo em consonância com o eu, o homem reedita um fenômeno semelhante ao delírio no paranoico, e isso ocorre pela condição fundante e virtual constituinte do eu (sempre um desconhecimento). Destacamos que, para o autor, o conhecimento não se equipara à ciência, a qual, por ser fundada na ordem do simbólico, não está na dependência do ponto de vista do eu, diferenciando-se da instância paranoica do conhecimento.

A tese da paranoia como matriz para o conhecimento humano, conforme estabelecida à luz da primeira abordagem da teoria do imaginário, em um segundo momento, sofrerá nova torção sob a visada do estruturalismo, quando Lacan começa sua aproximação com a linguística e, por meio dela, sua releitura de Freud. No Seminário 3 (As psicoses), ele vai se dedicar às estruturas fundantes do discurso delirante e formular uma dimensão nova na fenomenologia da psicose, na qual o sintoma encontra-se claramente amarrado às estruturas de linguagem.

Neste Seminário, nas elaborações sobre o registro do simbólico, Lacan retomará o Édipo, interpretando-o a partir da mediação simbólica da linguagem, condensando-o na substituição significante, em que a fórmula da metáfora paterna faz barrar o Desejo da Mãe, e resulta na inclusão do Nome-do-Pai enquanto significante que representa a lei do Outro e introduz a significação fálica e inscrição da castração, fazendo emergir, desta maneira, o significante do desejo. É a travessia desta operação, do Édipo enquanto metáfora simbólica, que permite ao sujeito dar significação aos seus significantes e advir como sujeito da linguagem. Este cruzamento pela ponte edípica insere o sujeito na estrutura, colocando-o frente à falta posta pela castração, e encarcerando-o ao recalque, obrigando-o a conviver com uma verdade sobre si que não pode ser dita por inteiro.

Desta maneira a metáfora paterna é apresentada como uma substituição, quando o Desejo da Mãe — em um primeiro momento, um significante enigmático para o sujeito - é barrado pelo Nome-do-Pai, significante que representa a lei no Outro e permite a inscrição fálica. Através desta falta abre-se a entrada do indivíduo no campo simbólico, tornando-o sujeito da linguagem e permitindo-lhe atribuir significações aos seus significantes. 
A travessia do Édipo não operada acaba por lançar o sujeito no campo da psicose: estrutura que vai ser entendida como uma posição subjetiva em que, ao apelo do Nome-do-Pai, virá como resposta ao sujeito uma ausência ou a carência do próprio significante, e o consequente fracasso da metáfora paterna. Assim se estabelece a forclusão do Nome-do-Pai na psicose, que implica a abolição da lei simbólica, impedindo a amarração das articulações do discurso para este sujeito.

O termo francês forclusion, traduzido por forclusão, é utilizado no campo jurídico como processo proscrito, ou seja, aquele do qual se perdeu o prazo e não se pode apelar, introduzindo-nos na dimensão da lei e de sua proscrição. Então, Lacan recorre ao Direito para esclarecer o mecanismo da Verwerfung, ou forclusão do Nome-do-Pai na psicose, que determina a posição do sujeito na estrutura, fora da lei simbólica, proscrita pela carência do significante fálico, que não estará presente para permitir a formulação da metáfora edípica.

No percurso estabelecido neste texto, verificamos que dois caminhos se abrem: o primeiro localiza a "paranoia”, que designará a estrutura mais universal do eu que se estabelece nas origens da primeira identificação, permitindo a Lacan atribuir a pré-condição paranoica ao conhecimento humano; o segundo destaca a paranoia que marcará a psicose como estrutura clínica.

Sobremaneira, a paranoia passa a nomear duas estruturas distintas: a primeira se refere à alienação como forma geral do imaginário; a segunda, à alienação psicótica. Como compatibilizar as duas teses?

A forma de conceber as duas noções de paranoia como conciliáveis, segundo Waldir Beividas (1999), é estabelecer uma diferença de estatuto entre elas, ou seja, verificar que não se encontram no mesmo registro. A primeira proposição, a da paranoia como matriz do conhecimento humano, não se limita ao registro clínico e, além de alcançar um valor epistemológico, funda a dialética do desejo. A segunda, a paranoia-forclusão, surge da epistemologia estrutural (método linguístico) para interpretar uma particularidade clínica: a estrutura psicótica.

Para abordar essa diferença de registro, retomamos o estádio do espelho conforme revisto à luz do simbólico, tendo como modelo o esquema ótico (LACAN,1958), que, a partir da introdução do Outro, definirá uma nova estrutura de percepção, na qual a imagem só se sustenta a partir de uma nomeação, estabelecendo uma alienação ainda mais radical que a imaginária: a simbólica.

Lacan vai usar o modelo ótico da experiência do buquê invertido, conforme descrita pelo professor $\mathrm{H}$. Bouasse, a fim de localizar a clivagem do simbólico e do imaginário e as relações entre o Eu ideal e o Ideal de eu (LACAN, 1958/1998).

Na figura 2, a experiência que Lacan utiliza para ilustrar a relação do imaginário com o real é feita com o espelho côncavo, uma esfera cortada em seu diâmetro com a face interna espelhada, tendo como característica a propriedade de reduplicar o objeto no mesmo lugar em que ele se encontra, se o mesmo for 
colocado entre o observador e o espelho. O objeto então colocado entre o espelho e o observador é uma mesa com um vaso em cima e um buquê de flores de cabeça para baixo, colado por baixo do tampo da mesa. Este é invisível para o observador, pois, do seu lado, a toalha cobre a parte inferior da mesa, embora não cubra o lado voltado para o espelho. A imagem produzida é invertida, pois os raios incidem inversamente, de forma a produzir uma imagem correta com as flores colocadas dentro do vaso.

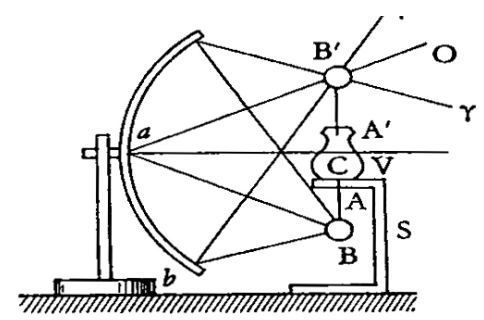

Figura 2. Esquema ótico (LACAN, 1958/1998, p.680)

Para se produzir esse efeito (imagem correta), o observador deve estar posicionado no cone $\left(\beta, B^{\prime} \gamma\right)$. No espelho esférico, essa é a imagem real, formada na mesma posição do objeto, o que a diferencia da imagem formada no espelho plano. Esta imagem é designada por i(a), que representa a imagem especular, real, do sujeito, precipitando a formação do corpo conforme metáfora proposta por Lacan (1958/1998): primeiramente, há um corpo descoordenado do qual sai um buquê de pulsões parciais; a partir de uma nova ação psíquica o vaso as unifica, compondo a imagem que dá sua unidade ao corpo, transformando essas flores em objetos do eu.

Na figura 3, utiliza-se o mesmo espelho côncavo cortado no diâmetro com a face interna espelhada. O objeto colocado entre o espelho e o observador é uma mesa com um buquê de flores em cima e um vaso de cabeça para baixo com o fundo colado por baixo do tampo da mesa, invisível para o observador. Nesse esquema, é acrescentado um espelho plano em frente à imagem real, em posição vertical paralela ao espelho côncavo, e o observador muda de lado. Desta forma, posicionado um pouco à frente do espelho côncavo, não vê o objeto embaixo da mesa, mas a imagem real refletida no espelho plano. Nesse esquema, o espelho plano representa o Outro do simbólico, e o que o observador vê nele é o reflexo da imagem real, ou seja, uma imagem virtual i'(a), que antecipa a unidade do corpo em uma alienação definitiva. Ambas as imagens estão no registro do imaginário, mas a segunda (virtual, mediada pela relação com o Outro) duplica a primeira (ilusão) e vai ter como referência o ponto I (ideal do Eu), onde situa o traço unário que comanda a autoimagem do sujeito. 


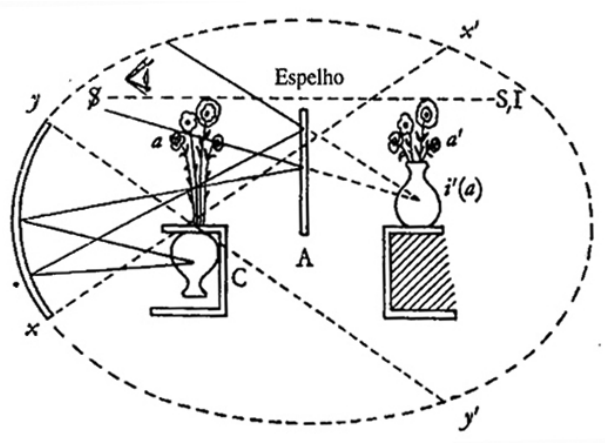

Figura 3. Esquema ótico (LACAN,1958/1998, p.681)

O esquema ótico é uma estrutura ordenada por leis permitindo a produção de uma imagem, mas na condição de que se introduza um sujeito representado pelo olho. Ele permite pensar a distinção entre o eu e o sujeito e a determinação do campo imaginário dada pelo simbólico, onde o Ideal do eu é o suporte simbólico que sustenta a imagem do eu — este considerado como eu Ideal, pois é discordante para sempre do corpo real. Isso nos indica que a constituição do sujeito e de seu eu se faz a partir da exterioridade (VODOVOSOFF, 1993).

O sujeito, então representado pelo olho, é apenas uma função, e sua posição define uma forma binária: no interior ou no exterior do cone de visão. Disso depende a constituição ou não da realidade, e também a fundação do eu. Para Lacan, a posição do olho, determinada pelo simbólico, indica a primazia deste sobre o imaginário e, por sua vez, esclarece que as variações do olho determinam a posição do sujeito na estrutura da linguagem.

Adrian Vodovosoff (op. cit) aponta que se pode observar um avanço do esquema ótico com relação ao estádio do espelho. Neste, a falta, enquanto falta de unidade do corpo, era explicada de forma objetiva com dados biológicos, sendo o problema circunscrito à prematuração do nascimento no homem, que acaba por desaparecer com o desenvolvimento orgânico. No esquema ótico, a falta representada pela perda da imagem real por um olho mal colocado nesta nova posição — é uma falta de estrutura. Não há desenvolvimento orgânico possível para o homem que lhe permitisse aceder a isto.

Retomamos a questão colocada anteriormente, que concerne ao fato de a paranoia nomear duas estruturas distintas. A partir da descrição do esquema ótico, propusemos localizar o sujeito psicótico - no caso, o paranoico - do lado direito da figura 2, e o neurótico, do lado esquerdo da figura 3, tendo como referência as posições distintas em relação ao simbólico: o paranoico tem a certeza de visualizar um vaso completo, ou a imagem real, e a introdução do real no imaginário não pode ser simbolizada por ele; já o neurótico, tomando 
como referência a figura do físico Bouasse, que também vê o vaso completo, ou a imagem virtual, sabe que a vê invertida somente porque o vaso está sob a mesa, podendo, dessa maneira, simbolizar, pela mediação do Outro, a discordância entre a imagem real e a virtual. Podemos, dessa maneira, estabelecer, com Lacan, a diferença entre a alienação psicótica e a alienação como forma geral do imaginário, conforme sinaliza no Seminário 3.

O esquema ótico evidencia o eu reduplicado por sua imagem especular, como o revirar de uma luva pelo avesso: movimento presente na constituição do eu que aponta a imagem enganosa do corpo como instância do desconhecer, fazendo do conhecimento humano (dupla alienação) matriz paranoica na eleição dos objetos do mundo. Lacan retoma esta questão utilizando o verbo co-naître, homófono de connaitre (conhecer), em um trocadilho que metaforiza o transitivismo do conhecimento:

“...essa união do sujeito com o objeto, como podemos reconhecê-la, é o ideal evocado desde sempre como princípio de uma teoria clássica do conhecimento, fundamentada na conaturalidade pela qual o conhecedor, em seu processo, vem a co-nascer no conhecido. Como não ver que é contra isto que se ergue toda a experiência psicanalítica...?” (LACAN,1958/1998, p.673)

Portanto, a paranoia que coincide com o sujeito representado pelo olho do observador posicionado do lado direito do desenho 2 (paranoia-forclusão), dada pela estrutura da psicose, localiza-se no campo clínico. Já a paranoia do sujeito representado pelo olho do observador que se situa do lado esquerdo do desenho 3 - que instaura a estrutura universal do eu e o desejo - pode ser localizada no campo epistêmico. Desta maneira, ambas as teses podem coexistir em estatutos diferentes.

Recebido em 28/4/2008. Aprovado em 9/6/2008.

\section{REFERÊNCIAS}

BEIVIDAS, W. (1999) “A psicose e o discurso da ciência”, in BIRMAN, J. (Org.) Sobre a psicose. Rio de Janeiro: Contra Capa.

COUTO, B. (1999) Trabalho intelectual coletivizado: produção, conhecimento e reconhecimento. Rio de Janeiro: UFRJ/IPPUR. (tese)

GEETS, C. (1941) Melanie Klein. Trad. Fernando de Castro Ferro; revisão de Amélia Thereza de Moura Vasconcelos. São Paulo: Melhoramentos; Editora da Universidade de São Paulo, 1977. 
GODOY, C. (2004) La paranoia en la enseñanza de Jacques Lacan. Bogotá: CID Centro de Investigación y Docencia en Psicoanálisis.

LACAN, J. (1932/1987) Da psicose paranoica e suas relações com a personalidade. Trad. Aluisio Menezes, Marco Antônio Coutinho Jorge e Potiguara Mendes Silveira Jr. Rio de Janeiro: Forense Universitária.

(1935/36) Compte rendu de le temps vecu. Études phénoménologiques et psychopatologiques de Eugène Minkowsk, dans Recherches philosofiques. [S.l.]: [s.ed.], p.424-431.

(1946) "Formulações sobre a causalidade psíquica", in Escritos. Rio de Janeiro: Jorge Zahar.

(1949/1998) "O estádio do espelho como formador da função do Eu”, in Escritos. Rio de Janeiro: Jorge Zahar.

. (1953) Some reflexions on the ego. International Journal of Psychoanalysis, v.34, p.11-17.

(1955-56/2002) “O Outro e a psicose”, in O Seminário livro 3. Rio de Janeiro: Jorge Zahar.

(1955-56/1998) "De uma questão preliminar a todo tratamento possível da psicose”, in Escritos. Rio de Janeiro: Jorge Zahar.

(1958/1998) "Observações sobre o relatório de Daniel Lagache", in Escritos. Trad. Vera Ribeiro. Rio de Janeiro: Jorge Zahar.

SAMUELS, A., SHORTER A. \& PLANT F. D (1986) Dicionário crítico de análise junguiana, Trad. Pedro Ratis, consultoria SBPA. Rio de Janeiro: Imago.

SIMANKE, R.T. (2002) Metapsicologia lacaniana — os anos de formação. São Paulo: Discurso Editorial; Curitiba: Editora da UFPR.

TEIXEIRA, A. M. R. (2004) "O conhecimento paranoico", in O tempo, o objeto e o avesso. Belo Horizonte: Autêntica.

VODOVOSOFF, A. (1993) Considerations sur le toule et moi par raposé à lídeal et le désir. Paris, 63p. Tradução livre da apostila manuscrita em francês. (mimeo)

WALLON, H. (1971) As origens do caráter na criança. Tradução de Pedro da Silva Dantas. São Paulo: Pensamento.

Simone de Fátima Gonçalves simonegoncalvesbh@gmail.com 
